\title{
ALÉM DE UM CONGRESSO...
}

\section{BEYOND A CONGRESS....}

\section{Átila Velho, TCBC*}

Durante os três anos em que estive envolvido na realização do XXV Congresso Brasileiro de Cirurgia do CBC, aproveitei todas as oportunidades para nominar aqueles que contribuíram para sua realização, ressaltando sempre a importância de nosso Presidente. Nesta oportunidade, entretanto, proponho ao leitor uma análise mais instigante e reflexiva sobre o tema.

Não deixo com isso, de atentar para a sua curiosidade, antecipando abaixo alguns dos dados que serão incluídos no relatório final a ser enviado ao Diretório Nacional.

No Congresso de Porto Alegre foram empregadas as mais variadas inovações técnicas, os mais elaborados recursos didáticos nos foram generosamente permitidos, foi empregada austeridade nos custos colaterais, foram mobilizados diversos segmentos sociais, incluindo o governador do estado, Germano Rigotto, cujo discurso esteve à altura da memória do Colégio e de seus membros; porém, não está entre esses, o núcleo do intrincado amálgama que modelou o Congresso; nenhum desses foi o acorde mais importante da sonora aprovação de nossos colegas.

O fato de ter sido acompanhada, ao detalhe, a realização do Congresso anterior, em São Paulo, foi vital para traçar a estratégia operacional e científica e serviu para que fossem previamente estabelecidos acordos com empresas que lá estavam, uma antecipação meritória sem dúvida, mas que não se compara ao atributo de que lhes falo.

Perfeccionistas, tivemos debates acalorados sobre muitos temas, e, divergindo respeitosamente, crescemos, como amigos e como afiliados do CBC. Muitos desses debates, diga-se de passagem, foram solucionados por colegas de longe, anonimamente, através de centenas de sugestões recebidas de todos os Capítulos e que foram acolhidas de forma singular, pois assoprava o minuano a importância desse gesto. Esboçávamos aqui, a qualidade "máter", intuitivamente cravávamos as estacas do evento sobre a mais pétrea laje em que se pode edificar qualquer iniciativa: o interesse comum.

O Congresso do Rio Grande permitiu compartir com colegas de todo o Brasil nossa autenticidade, e lhes permitiu sentir a motivação que transcendeu, sem menosprezar, o culto à ciência, ou seja, de valorizar as gentes. A resposta receptiva que foi dada, excedendo à expectativa, envolveu todos numa bruma de mais valia, uma espécie de orgulho original, que vai reverberar muito tempo ainda na alma dos cirurgiões gaúchos.

E é disto que lhes falo!+

Este Congresso Brasileiro de 2003 foi fruto regado e acarinhado durante muitos meses, colhido na boa vontade de nossos colegas, predispostos a serem condescendentes com nossas falhas e a enaltecerem nossas realizações, que também eram suas.

Organizar um Congresso como o do CBC, promove resultados internos e externos que vão além do que é possível dimensionar, e é por essa repercussão que deixo a sugestão de que seja criado um núcleo permanente de gestão, responsável por diretrizes básicas de sua realização, que possibilite incorporar e eliminar experiências anteriores e novas, mediante uma criteriosa análise de resultados, e que permita de uma vez por todas abandonarmos o "reinventar nosso de cada biênio".

Peço ao leitor, para deixar aqui duas mensagens. Uma é de que não esqueçamos para o futuro, de que o Congresso Brasileiro é uma oportunidade sem igual para o congraçamento, que

* Presidente da Comissão Científica - XXV Congresso Brasileiro de Cirurgia do CBC - Porto Alegre / Rio Grande do Sul.

+ P.S.: no momento em que encerro este editorial, recebo do Capítulo do Pará uma carta saudando o Congresso e ressaltando a solidariedade de todos com os acadêmicos e colegas daquele estado, envolvidos em um triste acidente no dia 05 de julho de 2003. 
como tudo o mais também precisa ser gestado. A outra é quanto a importância em estendê-lo corriqueiramente a outros estados, pois agregar culturas, respeitandoas, é tarefa prodigiosa e pode tornar o CBC um pólo de ainda maior representatividade, não pela homogeneidade que descaracteriza, mas pela consubstancialidade.
Encerro manifestando, em nome do Rio Grande do Sul, nossa honra e satisfação por havermos realizado o XXV Congresso Brasileiro do CBC e agradecendo a receptividade com que fomos brindados por todos os cebeceanos e por sua Diretoria.

Aos Capítulos candidatos ao Congresso de 2007 desejamos felicidades e boa sorte.

\section{Estrutura Científica do XXV Congresso Brasileiro de Cirurgia}

\begin{tabular}{|c|c|c|c|c|c|c|}
\hline Atwidades & Nümero & Sessoes & Heras & Palestrantes & Debatedores & Secretarios \\
\hline Pösteres & 605 & 55 & 40 & 0 & 55 & 0 \\
\hline Temas Livres & 1001 & 91 & 182 & 0 & 182 & 0 \\
\hline Temas Selecionados & 33 & 3 & 6 & 0 & 6 & 0 \\
\hline Videos Livies & 108 & 12 & 24 & 0 & 24 & 0 \\
\hline Videos Selecionados & 12 & 1 & 2 & 0 & 2 & 0 \\
\hline Simposios Especialidades & + & (6) & 60 & 120 & 24 & 24 \\
\hline Simpósios outros & & 3] & 12 & 12 & 3 & 3 \\
\hline Workshops & & 8 & 32 & 80 & 16 & 16 \\
\hline Cursos & & 2 & 20 & 30 & 6] & 6 \\
\hline Consensos & . & 11 & 3 & 120 & 1 & 0 \\
\hline Sessces interativas & 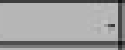 & 10 & 10 & 0 & 20 & 10 \\
\hline Sessóes Debates & . & 13 & 14 & 30 & 52 & 13 \\
\hline Encontros com Experts & & 10 & 20 & 10 & 10 & 10 \\
\hline Conforências & & 32 & 32 & 32 & 32 & 0 \\
\hline Mesas Redondas & & 33 & 66 & 165 & 33 & 33 \\
\hline Júri Simulado & & 1 & 2 & 7 & 2 & d \\
\hline TOTAL. & $175 \mathrm{~s}$ & 291 & 525 & 605 & 488 & 115 \\
\hline
\end{tabular}

* Por terem havido participações múltiplas, o número total de 1.188 convidados (total das 3 últimas colunas) deve ser reduzido em dois quintos, a fim de expressar um número aproximado de 713 convidados.

Freqüência dos Capítulos no Evento

\begin{tabular}{|lr|l|lr|}
\hline Rio Grande do Sul & 1059 & & Sergipe & 24 \\
Rio de Janeiro & 560 & & Maranhão & 23 \\
São Paulo & 525 & & Amazonas & 21 \\
Minas Gerais & 172 & & Não Informados & 21 \\
Santa Catarina & 164 & & Espírito Santo & 16 \\
Paraná & 160 & & Paraíba & 15 \\
Distrito Federal & 72 & & Mato Grosso & 12 \\
Pernambuco & 68 & & Roraima & 9 \\
Pará & 58 & & Mato Grosso do Sul & 8 \\
Bahia & 58 & & Acre & 5 \\
Goiás & 47 & & Tocantins & 4 \\
Alagoas & 28 & & Piauí & 3 \\
Rio Grande do Norte & 26 & & Internacional & 16 \\
Ceará & 26 & & TOTAL & $\mathbf{3 2 0 0}$ \\
\hline
\end{tabular}

